\title{
Enhanced exosome secretion in Down syndrome brain - a protective mechanism to alleviate neuronal endosomal abnormalities
}

\author{
Sébastien A. Gauthier ${ }^{1 \dagger}$, Rocío Pérez-González ${ }^{1 \dagger}$, Ajay Sharma ${ }^{1}$, Fang-Ke Huang ${ }^{2}$, Melissa J. Alldred ${ }^{1,3}$, \\ Monika Pawlik', Gurjinder Kaur', Stephen D. Ginsberg ${ }^{1,3,4,5}$, Thomas A. Neubert ${ }^{2,5}$ and Efrat Levy ${ }^{1,3,4,5,6^{*}}$ (D)
}

\begin{abstract}
A dysfunctional endosomal pathway and abnormally enlarged early endosomes in neurons are an early characteristic of Down syndrome (DS) and Alzheimer's disease (AD). We have hypothesized that endosomal material can be released by endosomal multivesicular bodies (MVBs) into the extracellular space via exosomes to relieve neurons of accumulated endosomal contents when endosomal pathway function is compromised. Supporting this, we found that exosome secretion is enhanced in the brains of DS patients and a mouse model of the disease, and by DS fibroblasts. Furthermore, increased levels of the tetraspanin CD63, a regulator of exosome biogenesis, were observed in DS brains. Importantly, CD63 knockdown diminished exosome release and worsened endosomal pathology in DS fibroblasts. Taken together, these data suggest that increased CD63 expression enhances exosome release as an endogenous mechanism mitigating endosomal abnormalities in DS. Thus, the upregulation of exosome release represents a potential therapeutic goal for neurodegenerative disorders with endosomal pathology.
\end{abstract}

Keywords: Down syndrome, endosome, extracellular vesicle, exosome, CD63, rab35

\section{Introduction}

A dysfunctional endosomal pathway and abnormally numerous and enlarged early endosomes are found within vulnerable Alzheimer's disease (AD) neurons early in life [7]. These characteristics are also seen in Down syndrome (DS) [10], a genetic disorder caused by trisomy of human chromosome 21 that leads to earlyonset AD [55]. Early endosomal abnormalities correlate with developmental brain abnormalities and intellectual disabilities in DS patients [35, 36, 54]. Dysfunction within the endosomal pathway, which occurs in several neurodegenerative disorders [53] in addition to AD and DS, results in the accumulation of material in neuronal endosomes with subsequent neuronal vulnerability and

\footnotetext{
* Correspondence: efrat.levy@nki.rfmh.org

${ }^{\dagger}$ Equal contributors

${ }^{1}$ Center for Dementia Research, Nathan S. Kline Institute for Psychiatric Research, Orangeburg, NY 10962, USA

${ }^{3}$ Department of Psychiatry, NYU Langone School of Medicine, New York, NY 10016, USA

Full list of author information is available at the end of the article
}

degeneration [39]. Early endosomal changes have also been observed in vitro in fibroblasts derived from DS individuals [8] and in neurons of well-established mouse models of DS $[9,26,44]$. In this study we have utilized the trisomic mouse model $\mathrm{Ts}\left[\mathrm{Rb}\left(12.17^{16}\right)\right] 2 \mathrm{Cje}$ [52] (hereafter called Ts2), which presents phenotypic and pathological features $[26,29,52]$ similar to the extensively studied Ts65Dn mouse model $[9,15,20,22]$, but has a genetic configuration with advantages in breeding [26, 32, 52].

Early endosomes are the first vesicular compartment along the endocytic pathway, which internalizes cargoes for delivery to late endosomes/multivesicular bodies (MVBs) for either degradation in lysosomes or for release into the extracellular space via exosomes. Exosomes are extracellular vesicles (EVs) formed as intraluminal vesicles (ILVs) by inward invagination of the membrane of MVBs, which are released into the extracellular space upon fusion of MVBs with the plasma membrane [12]. ILVs formation is regulated by the endosomal sorting complexes required for transport (ESCRT) 
machinery as well as by an ESCRT independent system that includes proteins from the tetraspanin family [11]. While most tetraspanins are present in the plasma membrane, CD63 is uniquely enriched in the membrane of MVBs [42]. Intracellular trafficking of MVBs towards the plasma membrane is regulated by several Rab GTPases and SNARE proteins [17]. Among them, rab35 likely plays a role in the docking of MVBs to the plasma membrane [24].

We investigated whether endosomal abnormalities affect the exosome secretory pathway in DS and explored the molecular mechanism underlying changes in exosome secretion in vivo in the brain of DS patients and the Ts 2 murine model, and in human DS fibroblasts grown in vitro. The results support the hypothesis that in neurodegenerative disorders with endosomal-lysosomal dysfunction, such as DS, exosome secretion serves as a disposal mechanism of toxic material that is abnormally accumulated in endosomal compartments. Given that endosomal abnormality causes neuron degeneration [39], mitigation of this pathology by enhanced exosome release can be expected to be protective and a target for therapeutic intervention.

\section{Materials and methods}

\section{Mice}

Ts[Rb(12.1716)]2Cje (Ts2) [52] and normal disomic (2N) littermates were studied at 3, 8, 12 and 24 months of age. Both females and males were used for all analyses. All animal procedures were performed following the $\mathrm{Na}$ tional Institutes of Health guidelines with approval from the Institutional Animal Care and Use Committee at the Nathan S. Kline Institute for Psychiatric Research.

\section{Human brain tissues}

Postmortem samples of Brodmann area 9 (BA9) obtained from human DS and control subjects (Table 1) were kindly provided by Dr. Jerzy Wegiel, Director, Brain Bank for Developmental Disabilities and Aging, Institute for Basics Research in Developmental Disabilities, Staten Island, New York. Tissue accession and use protocols were approved by the Nathan S. Kline Institute.

\section{EVs isolation from brain tissue}

EVs were isolated from frozen samples of cortical human brain region BA9 and from the right murine hemibrains (without the cerebellum and the olfactory bulbs). In each experiment, EVs were simultaneously isolated from a brain of either a DS patient or a Ts2 mouse and from an age-matched $2 \mathrm{~N}$ control. Brain EVs were isolated and purified as we have previously described [40, 41]. Briefly, frozen brain tissues were treated with 20 units $/ \mathrm{ml}$ papain (Worthington, Lakewood, NJ) in Hibernate A solution (HA, $3.5 \mathrm{ml} / \mathrm{sample;} \mathrm{BrainBits,} \mathrm{Springfield,} \mathrm{IL)} \mathrm{for}$
Table 1 Frozen samples of Brodmann area 9 from control (2N) and DS subjects

\begin{tabular}{|c|c|c|c|c|}
\hline \# & Genotype & Age & Gender & PMI (h) \\
\hline 1 & DS & 43 & $F$ & $>24$ \\
\hline 2 & $2 \mathrm{~N}$ & 31 & M & 3 \\
\hline 3 & DS & 43 & $F$ & NA \\
\hline 4 & $2 \mathrm{~N}$ & 32 & M & 14 \\
\hline 5 & DS & 59 & M & $>24$ \\
\hline 6 & $2 \mathrm{~N}$ & 59 & M & 6 \\
\hline 7 & DS & 59 & $\mathrm{~F}$ & NA \\
\hline 8 & $2 \mathrm{~N}$ & 67 & $\mathrm{~F}$ & 4 \\
\hline 9 & DS & 60 & $\mathrm{~F}$ & 22.5 \\
\hline 10 & $2 \mathrm{~N}$ & 68 & $\mathrm{~F}$ & 3 \\
\hline
\end{tabular}

Age is expressed in years

$P M I$ post mortem interval, NA not available

15 min at $37{ }^{\circ} \mathrm{C}$. The brain tissue was gently dissociated in $6.5 \mathrm{ml}$ of cold HA supplemented with protease inhibitors, centrifuged at $300 \mathrm{~g}$ for $10 \mathrm{~min}$ at $4{ }^{\circ} \mathrm{C}$ to discard the cells, and the supernantant was sequentially filtered through a $40 \mu \mathrm{m}$ mesh filter (BD Biosciences, San Jose, $\mathrm{CA}$ ) and a $0.2 \mu \mathrm{m}$ syringe filter (Corning Life Sciences, Teterboro, NJ). The filtrate was sequentially centrifuged at $4{ }^{\circ} \mathrm{C}$, at $2000 \mathrm{~g}$ for $10 \mathrm{~min}$ and $10,000 \mathrm{~g}$ for $30 \mathrm{~min}$ to discard membranes and debris, and at 100,000 $\mathrm{g}$ for 70 min to pellet the EVs. The EVs pellet was resuspended in $60 \mathrm{ml}$ of cold PBS (Thermo Fisher Scientific), and centrifuged at $100,000 \mathrm{~g}$ for $70 \mathrm{~min}$ at $4{ }^{\circ} \mathrm{C}$. The washed EVs pellet was resuspended in $2 \mathrm{ml}$ of $0.95 \mathrm{M}$ sucrose solution and inserted inside a sucrose step gradient column (six 2-ml steps starting from 2.0 M sucrose up to $0.25 \mathrm{M}$ ). The sucrose step gradient was centrifuged at 200,000 g for $16 \mathrm{~h}$ and fractions were collected from the top of the gradient. The fractions were diluted in cold PBS and centrifuged at $100,000 \mathrm{~g}$ for $70 \mathrm{~min}$. Sucrose gradient fraction pellets were resuspended in $30 \mu \mathrm{l}$ of cold PBS.

\section{Quantification of EVs levels in the brain}

Protein levels from the sucrose gradient purified fractions b, c and d, were quantified using the BCA Protein Assay Kit (Thermo Fisher Scientific). Acetylcholine esterase (AChE) activity assay, commonly used to quantify exosomes, was also performed on fractions b, c, and $\mathrm{d}$, as we have previously described $[40,41]$. Total EVs protein levels and EVs AChE activity were normalized to total brain sample protein content. AChE activity was additionally normalized to total EVs protein.

\section{Western-blot analyses}

Brain homogenates (10 $\mu \mathrm{g}$ protein), fibroblast lysates (10 $\mu \mathrm{g}$ protein), and EVs proteins (15 $\mu \mathrm{l}$ of the lysate corresponding to $25 \%$ of the EVs lysate total volume), 
were separated by $4-20 \%$ tris-glycine gel electrophoresis (Criterion precast gel, Bio-Rad, Hercules, CA) and transferred onto PVDF membranes (Immobilon, EMD Millipore, Billerica, MA). Membranes were incubated with antibodies to CD63 (1:250, Cat\# sc-15363, Santa Cruz Biotechnology, Dallas, TX), Alix (1:1000, Cat\# ABC40, EMD Millipore), TSG101 (1:1000, Cat\# 4A10, GeneTex, Irvine, CA), Flotillin-1 (1:1000, Cat\# 610821, BD Biosciences, San Jose, CA), Flotillin-2 (1:1000, Cat\# 610384, BD Biosciences), rab35 (1:1000, Cat\# 9690, Cell Signaling Technology, Danvers, MA), and $\beta$-actin (1:2500, Cat\# ab8226, Abcam, Cambridge, MA). The secondary antibodies used were HRP conjugated antirabbit, and anti-mouse antibodies (Jackson ImmunoResearch, West Grove, PA). Protein bands were quantified using ImageJ software (NIH, Bethesda, MD). All data are shown as the trisomic to diploid ratio for Ts 2 and $2 \mathrm{~N}$ mice, or for DS patients and $2 \mathrm{~N}$ control subjects.

\section{Proteomics \\ In-gel digestion}

EVs samples $(10 \mu \mathrm{g}$ protein for each sample) isolated from the brains of three Ts2 mice and three littermate controls were run into a $4 \%$ SDS-PAGE gel until all proteins entered the gel and stacked together. After staining by EZ-Run ${ }^{\text {Tx }}$ Protein Gel Staining Solution (Fisher BioReagents ${ }^{\mathrm{Tw}}$, Boston, PA) the gel bands were excised, reduced, alkylated, and digested in-gel with sequence grade modified trypsin (Promega, Madison, WI) as described [48]. Peptides were extracted by $50 \%$ acetonitrile in $5 \%$ formic acid, dried by vacuum centrifugation, and desalted using StageTips [43] packed with $\mathrm{C} 18$ beads.

\section{Liquid chromatography-MS/MS analysis}

A nanoflow HPLC instrument, EASY nLC 1000, was coupled directly to a Q Exactive $^{\mathrm{Tm}}$ HF Hybrid Quadrupole-Orbitrap Mass Spectrometer [47] (Thermo Fisher Scientific) with a nanoelectrospray ion source (Thermo Fisher Scientific). Capillary PicoFrit columns (New Objective, Woburn, MA) were packed in-house with PeproSil-Pur C18-AQ3 $\mu \mathrm{m}$ resin (Dr. Maisch $\mathrm{GmbH})$. Peptides were separated by a C18-reversed phase column (15 cm long, $75 \mu \mathrm{m}$ inner diameter) with a linear gradient of 3 to $40 \%$ acetonitrile in $0.1 \%$ formic acid at a flow rate of $250 \mathrm{~nL} / \mathrm{min}$ over $120 \mathrm{~min}$. The Q Exactive $^{\mathrm{Tx}}$ HF was operated in top 15 data-dependent mode with dynamic exclusion duration of $30 \mathrm{~s}$. Survey scans were acquired at a resolution of 120,000 at $\mathrm{m} / \mathrm{z}$ 200 and HCD spectra at a resolution of 15,000 at $\mathrm{m} / \mathrm{z}$ 200. Normalized collision energy was $27 \mathrm{eV}$.

\section{MS data processing and analysis}

The data analysis was performed with MaxQuant [13] software (Version 1.2.7.0, Max Planck Institute of Biochemistry) supported by Andromeda [14] to search a UniProt Mouse fasta database with 50,316 protein entries. Mass tolerance was set to $7 \mathrm{ppm}$ for peptide masses and $20 \mathrm{ppm}$ for HCD fragment ion masses with carbamidomethylation as a fixed modification and protein $\mathrm{N}$-terminal acetylation and methionine oxidation as variable modifications. Up to two missed cleavages were allowed while requiring strict trypsin specificity and minimum sequence length of seven. Peptides and proteins were identified with a false discovery rate (FDR) of $1 \%$. GO term enrichment analysis was done using Panther (http://geneontology.org/).

\section{Quantification of mRNA levels}

qPCR was performed on microdissected mouse hippocampi with RNA purified using the miRNAeasy mini kit (Qiagen, Germantown, MD). Taqman qPCR primers for CD63 (Mm01966817_g1) and rab35 (Mm01204416_ml) (Life Technologies) were utilized with samples assayed on a real-time qPCR cycler (7900HT, Life Technologies) in 96-well optical plates with coverfilm as described previously $[2-4,18,29]$. The ddCT method was employed to determine relative gene level differences between Ts2 and $2 \mathrm{~N}$ mice $[1,3,4,29]$. Succinate Dehydrogenase Complex Flavoprotein Subunit A (Sdha, Mm01352360_m1) qPCR products were used as a control housekeeping gene. Negative controls consisted of the reaction mixture without input RNA and reaction mixture without Superscript III enzyme. PCR product synthesis was modeled as a function of mouse genotype, using mixed effects models to account for the correlation between repeated assays on the same mouse [37].

\section{Cell culture and interference RNA (siRNA) depletion}

Forearm skin fibroblasts from DS patients (Cat\#AG076985, Coriell Institute for medical research) and age-matched $2 \mathrm{~N}$ control subjects (\#AG06922, Coriell Institute for medical research) were grown in Dulbecco's modified Eagle's medium (DMEM, Thermo Fisher Scientific) supplemented with $10 \%$ fetal bovine serum (FBS, Thermo Fisher Scientific), 100 units $/ \mathrm{ml}$ of penicillin and $100 \mu \mathrm{g} / \mathrm{ml}$ streptomycin (Thermo Fisher Scientific), $2 \mathrm{mM}$ GlutaMAX (Thermo Fisher Scientific) at $5 \% \mathrm{CO}_{2}$ at $37{ }^{\circ} \mathrm{C}$ in humidified air. Experiments were performed on DS and $2 \mathrm{~N}$ cells with passage numbers from P8 to P14. Cells were seeded in P100 dishes with $12 \mathrm{~mm}$ coverslips at 300,000 (2N) or 350,000 (DS) cells per dish. The difference in the number of cells is because of a difference in division time. Transfection of siRNA was performed by combining $8 \mu \mathrm{l}$ of siPORT Amine agent (Thermo Fisher Scientific) in $250 \mu \mathrm{l}$ Opti-MEM (Thermo Fisher Scientific) with $250 \mu \mathrm{l}$ Opti-MEM 
containing either CD63 siRNA (Cat\# hs.Ri.CD63.13.2, Integrated DNA Technologies, Coralville, IA) or negative control siRNA (Integrated DNA Technologies). Cells were incubated with transfection complexes for $4 \mathrm{~h}$ and the medium was replaced with medium containing EVsdepleted FBS as described below.

\section{EVs isolation from fibroblast-conditioned media and quantification of exosome secreted levels}

EVs were isolated from conditioned media of DS and diploid controls fibroblasts. Cell culture media were replaced with DMEM supplemented with 10\% FBS, which was depleted of EVs by ultracentrifugation at $100,000 \mathrm{~g}$ for $70 \mathrm{~min}, 100 \mathrm{units} / \mathrm{ml}$ of penicillin and $100 \mu \mathrm{g} / \mathrm{ml}$ streptomycin (Thermo Fisher Scientific), and 2 mM GlutaMAX (Thermo Fisher Scientific). The conditioned media were collected every $24 \mathrm{~h}$ and fresh medium was added to the cells over 3 days. EVs were isolated from the conditioned media as previously described [50]. Briefly, conditioned media were centrifuged at $300 \mathrm{~g}$ for $10 \mathrm{~min}$. The supernatant was sequentially centrifuged at $2000 \mathrm{~g}$ for $10 \mathrm{~min}$, at $10,000 \mathrm{~g}$ for $30 \mathrm{~min}$, and finally at 100,000 g to pellet the EVs. The EVs were resuspended in cold PBS and then centrifuged at $100,000 \mathrm{~g}$. The washed EVs pellet was resuspended in PBS and lysated in $2 \mathrm{X}$ radioimmune precipitation assay (RIPA) buffer. Equal volumes of EVs lysates were loaded on the electrophoresis gel. Exosome levels were quantified by intensity of the bands obtained by Western-blot analysis of the exosomal markers CD63, Alix, and TSG101 using the ImageJ software (NIH).

\section{Morphometric analyses of endosomes}

DS and $2 \mathrm{~N}$ control fibroblasts grown on glass coverslips were fixed with cold 2\% PFA in PBS for 20 min, subsequently blocked with 10\% FBS for $1 \mathrm{~h}$ at room temperature, and incubated overnight with the antiEEA1 antibody (1:200, Cat\# 07-1820, EMD Millipore) at $4{ }^{\circ} \mathrm{C}$. Cells were incubated with the secondary antibody Alexa 568 (1:500, Cat\# A11036, Thermo Fisher Scientific) for $1 \mathrm{~h}$ at room temperature. Confocal microscopy was carried out using a LSM 510 microscope (Carl Zeiss). For the quantification of EEA1 staining, digital images were taken at $\times 63$ magnification with comparable background intensities among conditions. The number of EEA1-positive endosomes and the endosomal area per cell were analyzed for each fibroblast in captured images taken in a single plane of focus by the ImageJ morphometry software (NIH) by a genotype- and condition-blinded observer. Individual fibroblasts and EEA1-positive endosomes were outlined and area measured. For each condition, a total of 20 fibroblasts per experiment were assessed at random from several fields.

\section{Statistical analyses}

Data are presented as mean \pm SEM. Unpaired, twotailed, Student's t-test statistical analysis were used to compare differences in EVs levels in DS brains and $2 \mathrm{~N}$ controls, Ts2 brains and age-matched $2 \mathrm{~N}$ controls, and to compare protein levels in Ts2 EVs, DS brain homogenates and DS fibroblast cell lysates to $2 \mathrm{~N}$ controls. qPCR results were analyzed using one-way ANOVA and posthoc analysis (Neumann-Keuls test; level of statistical significance was set at $p<0.05)$. Unpaired, two-tailed, Student's t-test statistical analyses were used to determine in vitro differences in exosome secretion between untreated $2 \mathrm{~N}$ with DS cells, and within the same line transfected with CD63 siRNA as compared to cells transfected with negative control siRNA. Endosomal changes in $2 \mathrm{~N}$ and DS cells were assessed by one-way ANOVA followed by Tukey post-hoc multiple comparison test.

\section{Results}

Higher levels of EVs in the brain of DS patients and Ts2 mice compared to diploid controls

Brain EVs were isolated as previously described $[40,41]$ from DS patients and age-matched normal controls (Table 1), and from the right hemibrain of 3-, 8-, 12and 24-month-old Ts2 mice and $2 \mathrm{~N}$ littermates. Separation of the EVs on a sucrose gradient resulted in 7 fractions, from a, the least dense, to $g$, the densest fraction, and Western-blot analysis showed that fractions with densities higher than 1.07 and lower than 1.17 (fractions $\mathrm{b}, \mathrm{c}$ and $\mathrm{d}$ ) were immunoreactive to Flotillin-1 and Flotillin-2, lipid raft proteins found in EVs, and established exosomal markers (Fig. 1a). Quantification of the exosome-enriched EVs fractions b, c, and d was performed by measuring the total protein content in the fractions normalized to total protein content in the brain tissue. In the samples of the frontal cortex of DS patients we found higher EVs levels compared to $2 \mathrm{~N}$ controls $(\mathrm{DS} / 2 \mathrm{~N}$ ratio $=1.39, p=0.022)$ (Fig. 1b). A similar increase in EVs levels was found in the brain extracellular space of the DS mouse model Ts 2 at $12(\mathrm{Ts} 2 / 2 \mathrm{~N}$ ratio $=1.20, p=0.0054)$ and $24(\mathrm{Ts} 2 / 2 \mathrm{~N}$ ratio $=1.29$, $p=0.048)$ months of age compared to littermate controls, but not in younger, $3-(\mathrm{Ts} 2 / 2 \mathrm{~N}$ ratio $=1.08$, $p=0.31)$ and 8 -month-old $(\mathrm{Ts} 2 / 2 \mathrm{~N}$ ratio $=1.18$, $p=0.16$ ) mice (Fig. 1c). We also measured the levels of exosome-enriched EVs by quantifying the activity of $\mathrm{AChE}$, a protein that is specifically sorted into exosomes $[27,46]$. The AChE activity measurements were normalized to total protein content in the brain tissue and the results supported the finding of DS-induced higher levels of exosomes with a trend in the brain extracellular space of DS patients $(\mathrm{DS} / 2 \mathrm{~N}$ ratio $=1.29, p=0.14)(\mathrm{Fig}$. $1 \mathrm{~d})$, and conclusively in $12-(\mathrm{Ts} 2 / 2 \mathrm{~N}$ ratio $=1.26$, 

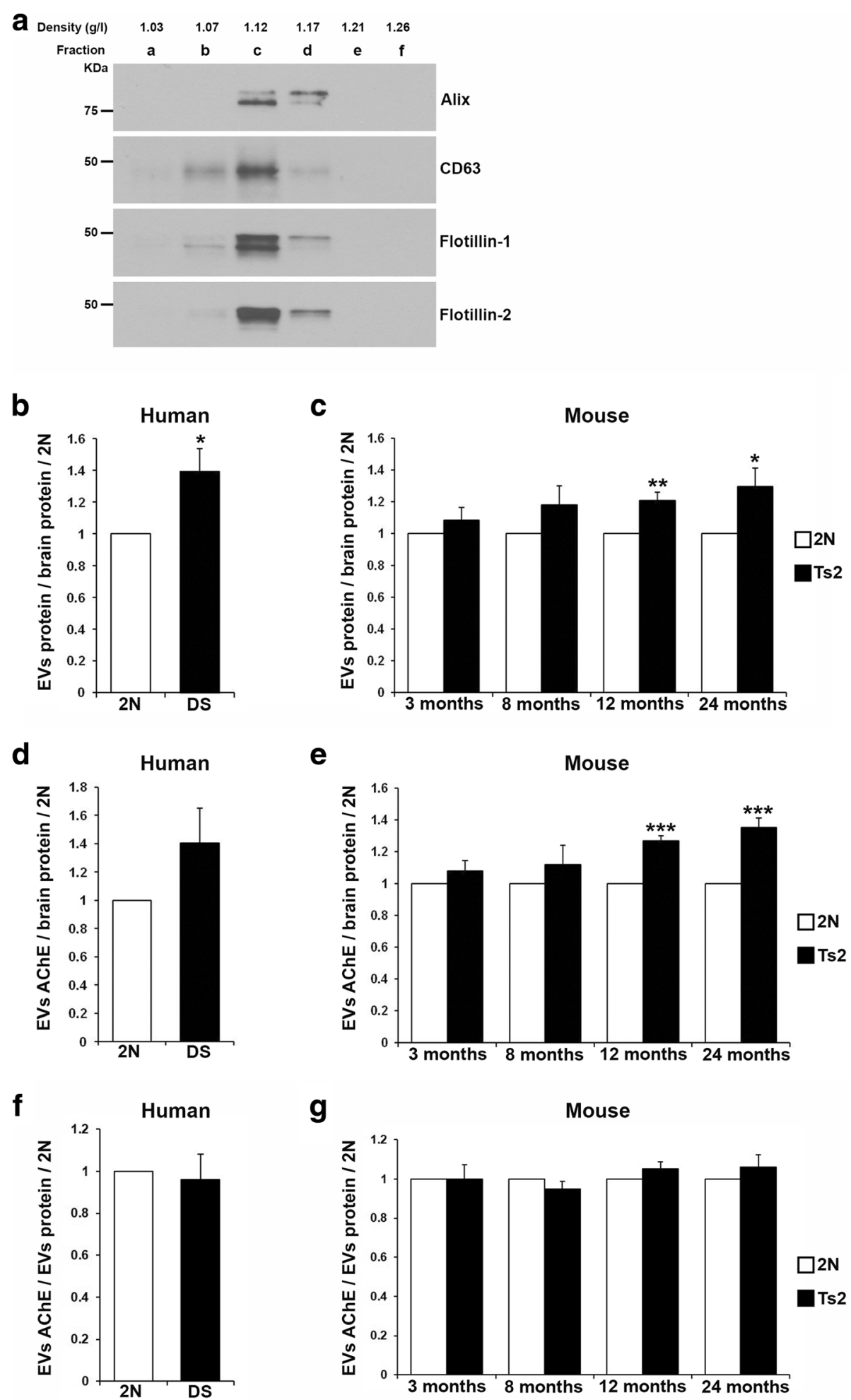

Fig. 1 (See legend on next page.) 
(See figure on previous page.)

Fig. 1 Higher levels of exosome-enriched EVs in the brains of DS patients and of Ts2 mice as compared to age-matched diploid controls. a Representative Western-blots of EVs isolated from human brain tissue and purified on a sucrose step gradient column. The sucrose gradient fractions b, c and d showed the presence of the exosomal proteins Alix and CD63, and the EVs proteins Flotillin-1 and Flotillin-2. b Quantification of total protein levels of EVs isolated from the brain extracellular space of DS patients, normalized to brain tissue protein levels, showed higher EVs levels compared to controls. $\mathbf{c}$ Higher EVs levels were also found in the brain extracellular space of 12- and 24-month-old Ts2 mice compared to 2N littermates. No significant differences were found in total EVs protein levels of 3- and 8-month-old Ts2 mice compared to controls. Similar results were obtained when AChE activity levels were measured in EVs isolated from the brain extracellular space of DS patients (d) and Ts2 mice (e) as compared to $2 \mathrm{~N}$ controls when normalized to brain tissue protein content. AChE activity levels normalized to EVs protein content were not different between brains of DS patients ( $\mathbf{f}$ ) and Ts 2 mice (g) compared to $2 \mathrm{~N}$ controls. EVs levels are presented as trisomic to $2 \mathrm{~N}$ ratio. Student t-test, $n=5$ (DS and $2 \mathrm{~N}$ human brains), $n=4$ (3- and 24-month-old), $n=5$ (8-month-old), and $n=7$ (12-month-old) brains of Ts2 and 2N mice $\left({ }^{*} p<0.05 ;{ }^{* *} p<0.01 ;{ }^{* * *} p<0.001\right)$

$p=0.00016)$ and 24 -month-old $(\mathrm{Ts} 2 / 2 \mathrm{~N}$ ratio $=1.35$, $p=0.00081$ ) Ts2 mice (Fig. 1e). No significant differences in the levels of AChE activity were found in the brains of 3- (Ts $2 / 2 \mathrm{~N}=1.08, p=0.28)$ and 8-month-old $(\mathrm{Ts} 2 / 2 \mathrm{~N}=1.12, p=0.34)$ Ts 2 mice compared to $2 \mathrm{~N}$ littermates (Fig. 1e). Additionally, AChE activity was normalized to EVs protein content instead of total protein in the brain to estimate the AChE levels per EV. AChE activity levels per EV in the brains of DS patients were not different from $2 \mathrm{~N}$ controls $(\mathrm{DS} / 2 \mathrm{~N}$ ratio $=0.96$ ) (Fig. 1f), similar to the levels of AChE per EV in the brains of $3-(\mathrm{Ts} 2 / 2 \mathrm{~N}$ ratio $=1.00), 8-(\mathrm{Ts} 2 / 2 \mathrm{~N}$ ratio $=0.95), 12-$ $(\mathrm{Ts} 2 / 2 \mathrm{~N}$ ratio $=1.05)$ and $24-$ month-old $(\mathrm{Ts} 2 / 2 \mathrm{~N}$ ratio $=1.06)$ Ts 2 mice compared to age-matched $2 \mathrm{~N}$ controls (Fig. 1g). Altogether these results argue that higher number of exosome-enriched EVs loaded with similar levels of $\mathrm{AChE}$ are present in the brain extracellular space of DS patients and 12- and 24-month-old Ts2 mice compared to $2 \mathrm{~N}$ controls.

\section{Higher content of CD63 and rab35, regulators of ILVs} generation and release, in Ts2 brain EVs as compared to $2 \mathrm{~N}$ To identify candidate proteins whereby a change in expression could be mechanistically linked to increased levels of exosome-enriched EVs in DS, we performed label-free liquid chromatography-mass spectrometry (LC-MS)-based proteomics on EVs (pooled from the sucrose gradient fractions $\mathrm{b}, \mathrm{c}$, and $\mathrm{d}$ ) isolated from the brains of 12-month-old Ts 2 and $2 \mathrm{~N}$ littermates. We identified 1587 and 1659 proteins in $2 \mathrm{~N}$ and Ts2 EVs samples, respectively, with a large overlap in protein identification between biological replicates: 1252 common proteins in the samples from three $2 \mathrm{~N}$ mice (Fig. 2a), and 1363 common proteins in the samples from three Ts2 mice (Fig. 2b). 1549 proteins were common to both genotypes (Fig. 2c). Gene ontology (GO) enrichment analysis of the common proteins identified by LC-MS showed that the most abundant components were proteins characteristic of vesicles, extracellular vesicles, extracellular organelles, and exosomes (Fig. 2d). Among the top 100 proteins that are often identified in exosomes (Exocarta, exosome database available online; http://www.exocarta.org/) 70 were identified in this study (Additional file 1: Table S1). Thus, using an unbiased approach, this analysis confirmed that vesiclerelated proteins are highly enriched in brain EVs preparations, with specific enrichment of exosomal proteins.

The LC-MC analysis revealed a trend for higher levels of CD63 and rab35 in Ts2 EVs compared to $2 \mathrm{~N}$ that was confirmed and found to be significantly different by Western-blot analysis (Fig. 2e).

\section{Higher protein expression levels of CD63 and rab35 in DS brains}

To determine whether the differences found in EVs protein levels reflect differences in protein expression levels within the cell leading to changes in exosome secretion, we analyzed the expression levels of CD63 and rab35 in human brain homogenates by Western-blot. Higher expression levels of CD63 (DS/2N ratio $=1.53 ; p=0.030)$ and rab35 $(\mathrm{DS} / 2 \mathrm{~N}$ ratio $=1.85 ; p=0.034)$ were observed in the frontal cortex of human DS patients as compared to $2 \mathrm{~N}$ controls (Fig. 3a). In contrast, no significant differences were detected in the levels of the exosomal markers Alix (DS/2N ratio $=1.12 ; p=0.66)$ and TSG101 $(\mathrm{DS} / 2 \mathrm{~N}$ ratio $=1.03 ; p=0.88)$ between DS and $2 \mathrm{~N}$ controls (Fig. 3b).

\section{Enhanced exosome secretion by DS fibroblasts}

Given the endosomal abnormalities observed in cultured human forearm skin fibroblasts isolated from DS patients [8], similar to the brains of DS patients [10] and Ts2 mice [26], we hypothesized that exosome release into the media will be enhanced in order to alleviate the endosomal pathology. Western-blot analysis of EVs secreted into cultured media was performed with antibodies to CD63, rab35, Alix, and TSG101. Quantification of the bands and normalization to total cell proteins revealed that the levels of CD63 (DS/2N ratio $=1.70, p=0.023)$, Alix $(\mathrm{DS} / 2 \mathrm{~N}$ ratio $=1.60$, $p=0.030)$ and TSG101 (DS/2N ratio $=1.56, p=0.022)$ were higher in DS EVs compared to $2 \mathrm{~N}$ controls (Fig. 4a). The rab35 protein was not detected in fibroblasts EVs, potentially due to low content. We also studied the levels of these proteins in cell lysates and found that the expression levels of $\mathrm{CD} 63(\mathrm{DS} / 2 \mathrm{~N}$ ratio $=2.30$, 
a

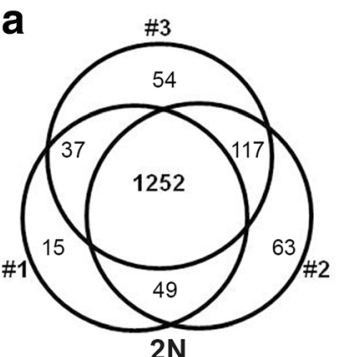

d

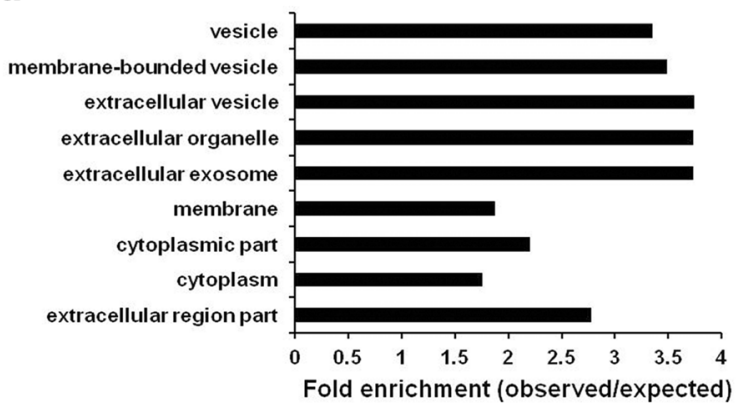

e

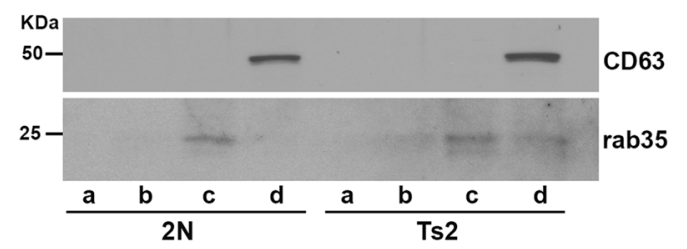

b

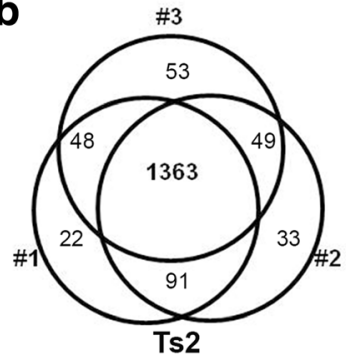

C

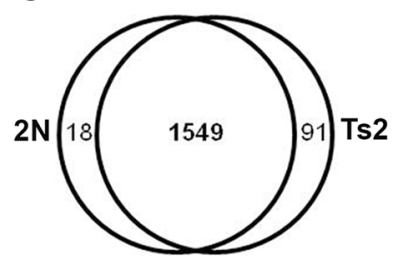

3.63E-236

$2.55 \mathrm{E}-232$

3.3E-211

9.7E-211

$1.27 \mathrm{E}-208$

$1.87 \mathrm{E}-182$

$6.35 \mathrm{E}-177$

$8.59 \mathrm{E}-159$

7.16E-155

prave

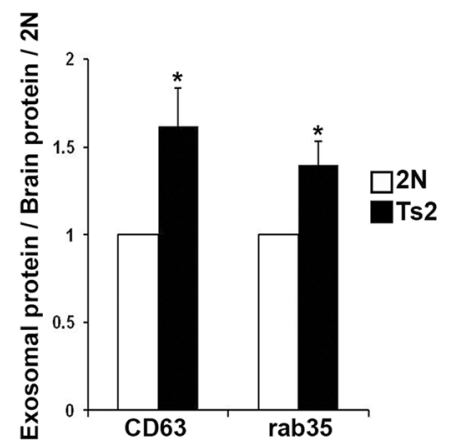

Fig. 2 Proteomic analysis of exosome-enriched mouse brain EVs. A Venn diagram shows the overlap between biological replicates within each genotype for $2 \mathrm{~N}$ (a) and Ts2 (b) EVs. c 1549 proteins were common to both genotypes. 91 and 18 proteins were unique to Ts2 and 2N samples, respectively. $\mathbf{d}$ GO analyses for components of the 1549 proteins common to both genotypes revealed enrichment of extracellular vesicles and exosomal proteins in the EVs preparations. $P$-values for each cellular category are shown on the right. e Representative Western-blots with anti-CD63 and anti-rab35 antibodies of the $2 \mathrm{~N}$ and Ts2 sucrose gradient EVs fractions and corresponding quantification. Student t-test, $n=7\left({ }^{*} p<0.05\right)$

$p=0.0016)$ and rab35 $(\mathrm{DS} / 2 \mathrm{~N}$ ratio $=1.56, p=0.024)$ were higher in DS than in $2 \mathrm{~N}$ fibroblasts (Fig. $4 \mathrm{~b}$ ), consistent with the observation in DS postmortem brain (Fig. 3a). However, the levels of Alix (DS/2N ratio $=0.62$, $p=0.13)$ and TSG101 (DS/2N ratio $=0.95 p=0.754)$ were not significantly different in the cell lysates obtained from DS as compared with $2 \mathrm{~N}$ fibroblasts (Fig. 4c). Thus, the higher EVs levels of Alix and TSG101 in the media cultured by DS fibroblasts are due to higher levels of exosome secretion by DS fibroblasts as compared to $2 \mathrm{~N}$ cells.

\section{Higher mRNA levels of CD63 but not rab35 in Ts2 brains}

To determine whether differences in CD63 and rab35 protein levels were due to differences in mRNA levels, qPCR analyses were performed on RNA extracted from the hippocampus of 12-month-old Ts2 and 2N littermates. Upregulation of CD63 RNA expression was observed in Ts 2 brains as compared with $2 \mathrm{~N}$ controls ( $29 \%$ higher $p=0.0286$; ddCt values expressed as mean \pm SEM were $2.3558 \pm 0.1966$ in $2 \mathrm{~N}$ and $3.0382 \pm 0.1954$ in DS; $n=5$ per genotype). No significant difference was found for rab35 transcript levels.

A role for CD63 in exosome secretion as a mechanism to modulate endosomal pathology

We induced a CD63 loss of function in fibroblasts to investigate the role played by CD63 in the regulation of exosome secretion. Our small interfering RNA (siRNA) strategy targeting CD63 transcripts successfully knocked down CD63 levels in 2N and DS fibroblasts (Fig. 5a). The reduction in CD63 expression was $77.68 \pm 5.1 \%$ and 

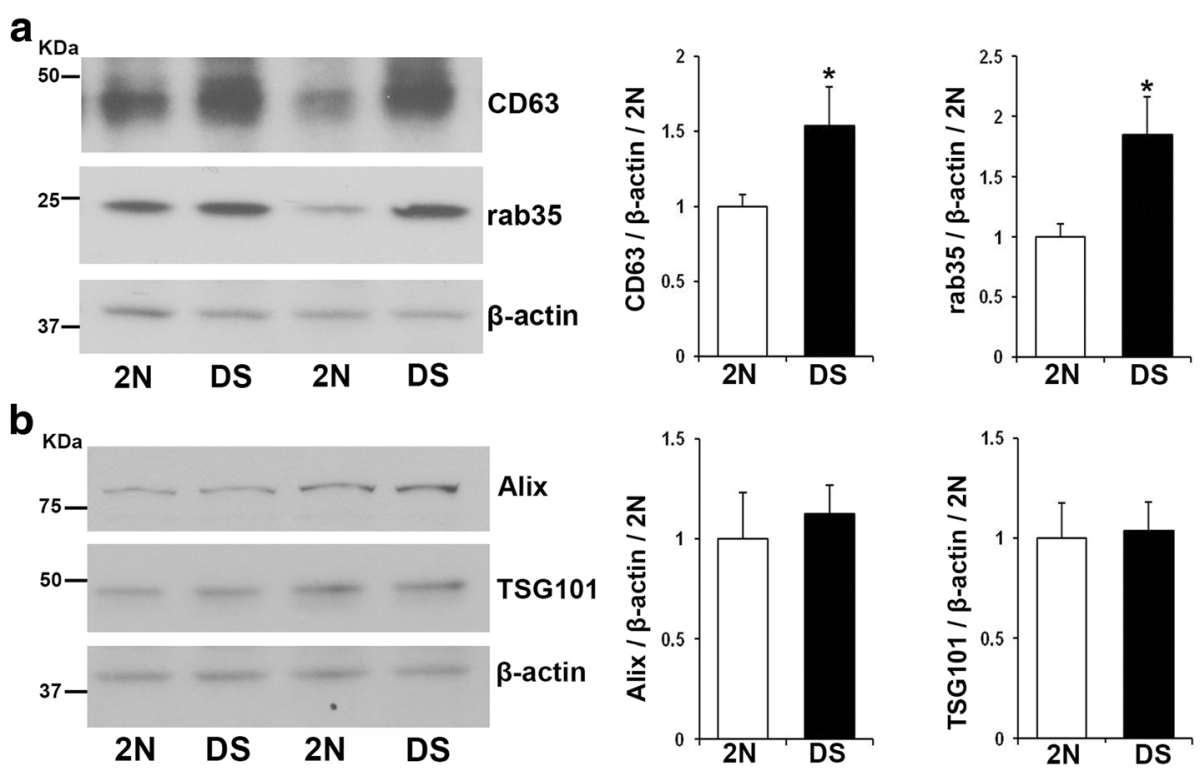

Fig. 3 Enhanced expression of the proteins CD63 and rab35 in DS brains. a Representative Western-blots (corresponding to samples number 3, 2, 5 and 4 in Table 1) and quantification showing the overexpression of CD63 and rab35 in DS brains compared to $2 \mathrm{~N}$. $\mathbf{b}$ No differences in the levels of Alix or TSG101 were detected in homogenates of human DS brains compared to $2 \mathrm{~N}$ controls. $\beta$-actin was blotted as an internal control for loading. Student t-test, $n=5\left({ }^{*} p<0.05\right)$

$73.03 \pm 3.9 \%$ for $2 \mathrm{~N}$ and DS cells, respectively. The exosomes secreted into the medium over the course of three days after the transfection were quantified by Westernblot analysis (Fig. 5b). No significant changes were found in exosome secretion by $2 \mathrm{~N}$ cells following CD63 knockdown as evidenced by similar levels of Alix (CD63/control siRNA ratio $=1.01, p=0.37)$ and TSG101 $(\mathrm{CD} 63 /$ control siRNA ratio $=1.07, p=0.25$ ) (Fig. 5c). The levels of CD63 in 2N EVs showed a trend to decrease (CD63/ control siRNA ratio $=0.70, p=0.08)$, which was expected due to CD63 knockdown. In contrast, reducing CD63 expression led to lower levels of exosomes secreted into the cell culture media by DS fibroblasts as seen by reduced levels of exosomal Alix (CD63/control siRNA ratio $=0.82, p=0.02)$, TSG101 $(\mathrm{CD} 63 / \mathrm{control}$ siRNA ratio $=0.73, p=3.7 \times 10^{-7}$ ) and, as expected, CD63 (CD63/control siRNA ratio $=0.56, p=4.8 \times 10^{-6}$ ) (Fig. 5d). When the expression levels of Alix and TSG101 were normalized to EVs protein content, no changes were detected in the levels of Alix (CD63/control siRNA ratio $=1.04, p=0.69)$ and TSG101 $(\mathrm{CD} 63 /$ control siRNA ratio $=0.95, p=0.76$ ) in EVs from DS cells in which CD63 was reduced compared to controls, indicating that the loading levels of Alix and TSG101 per EV are similar after CD63 knockdown in DS cells. Therefore, the lower intensity of the bands for Alix and TSG101 shown in Fig. 5b is the result of lower number of EVs and rules out the possibility that CD63 knockdown is responsible for a change in EVs composition.
To determine whether changes in exosome secretion affect endosomal compartments, endosomal morphology was studied in $2 \mathrm{~N}$ and DS fibroblasts using early endosome antigen 1 (EEA1) immunocytochemistry (Fig. 5e). As previously demonstrated [8], the number (Fig. 5f) and area (Fig. 5g) of endosomes were significantly higher in DS cells compared to $2 \mathrm{~N}$. While CD63 knockdown did not affect endosomes in $2 \mathrm{~N}$ cells (Fig. $5 \mathrm{f}$-g), the number of endosomes was higher (Fig. 5f) and a trend to increased endosomal area (Fig. 5g) was observed in DS fibroblasts in which CD63 expression was reduced compared to DS cells transfected with negative control siRNA.

\section{Discussion}

Different types of EVs have distinct intracellular origin, including plasma membrane-derived microvesicles, apoptotic vesicles, and MVBs-derived exosomes (reviewed in $[28,30,51])$. We found higher levels of EVs in the brain extracellular space of DS patients and Ts2 mice compared to controls. Proteomic analysis confirmed that exosomal proteins were highly enriched in the brain EVs preparations, and identified higher levels of the exosomal marker CD63 and the exosome-related protein rab35 in brainderived Ts2 EVs compared to $2 \mathrm{~N}$. These LC-MS data suggest that the higher levels of EVs found in the brain extracellular space of DS patients and Ts2 are due to higher levels of exosomes. The brains of DS patients at advanced ages likely have significant AD neuropathology, not present in age-matched control brains, raising the possibility that enhanced exosome secretion is due to $\mathrm{AD}$ 

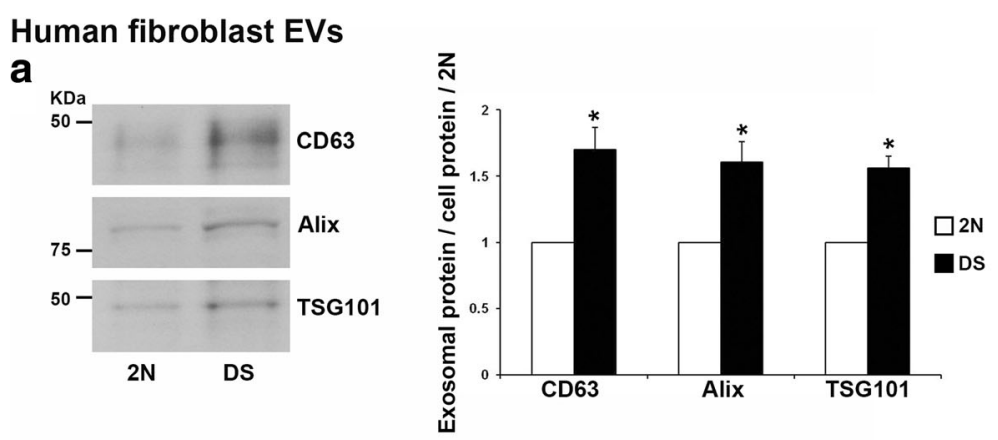

\section{Human fibroblast cell lysates}

b
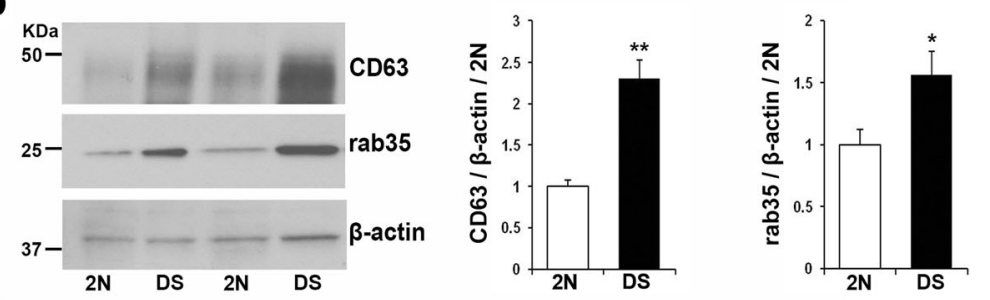

C
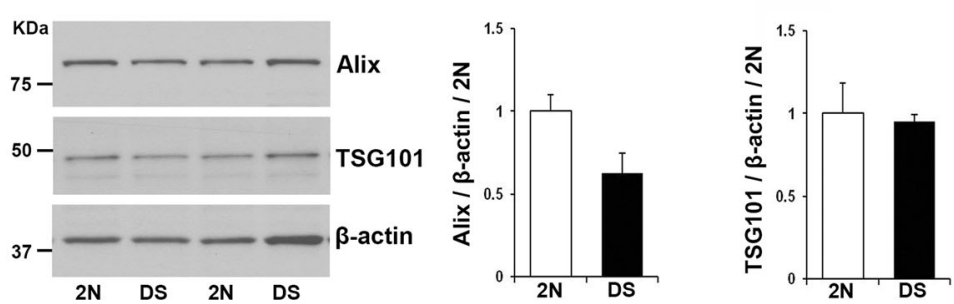

Fig. 4 Exosome secretion is enhanced by DS fibroblasts as compared to $2 \mathrm{~N}$ controls. a Representative Western-blots and corresponding quantification showing the higher levels of the exosomal markers CD63, Alix and TSG101 in EVs isolated from the conditioned media of DS fibroblasts compared to $2 \mathrm{~N}$ controls. The intensity of the bands was normalized to cell protein. $\mathbf{b}$ Elevated expression levels of CD63 and rab35 and (c) no differences in the levels of Alix and TSG101 in lysates of DS fibroblasts compared to $2 \mathrm{~N}$ controls, as shown by the representative Western-blots and corresponding quantification. $\beta$-actin was blotted as an internal control for loading. Student t-test, $n=5$ independent experiments $\left({ }^{*} p<0.05 ;{ }^{* *} p<0.01\right)$

neuropathology. However, we have previously reported that $\operatorname{Tg} 2576$ mice, overexpressing APP, do not secrete more exosomes than their littermate controls at an age when amyloid pathology has fully developed [40], suggesting that $\mathrm{AD}$ neuropathology is not causing higher exosome secretion. Further, we found that DS fibroblasts secrete more exosomes into the cell culture media than $2 \mathrm{~N}$ cells. This suggests that the higher exosome levels found in vivo is a consequence of enhanced exosome secretion rather than altered exosome stability or less exosome clearance in the brain extracellular space.

Once early endosomal cargoes are delivered to late endosomes there are two possible fates, either lysosome degradation or exosome release. The endosomal function under conditions of increased early endosomal drive in DS [8] would require a corresponding increase in either or both of these pathways. Since we measured a statistically enhanced exosome secretion in the brain of 12-month-old and older Ts2 mice and the endosome enlargement phenotype is observed in neurons of 4- month-old mice [26], we hypothesize that enhanced exosome secretion constitutes a delayed cellular response designed to lower the size and number of endosomal compartments in DS by shedding more endosomal content into the brain extracellular space (Fig. 6). A similar mechanism of exosome release was suggested for the cell to partially overcome the accumulation of free cholesterol within late endosomes/lysosomes in the Niemann-Pick Type C disease [49].

The expression levels of the ESCRT proteins Alix and TSG101 did not differ in the brains of human DS patients and in DS fibroblasts as compared with $2 \mathrm{~N}$ controls. These data suggest that the ESCRT machinery is not the trigger behind enhanced exosome secretion. We found that CD63 is overexpressed in DS brains and in DS fibroblasts compared to $2 \mathrm{~N}$ controls. Similarly, a recent study reported higher protein levels of another member of the tetraspanin family, tetraspanin-6, in the brains of AD patients, and in vitro experiments related tetraspanin- 6 overexpression to the generation of more 
a

Fibroblast cell lysates

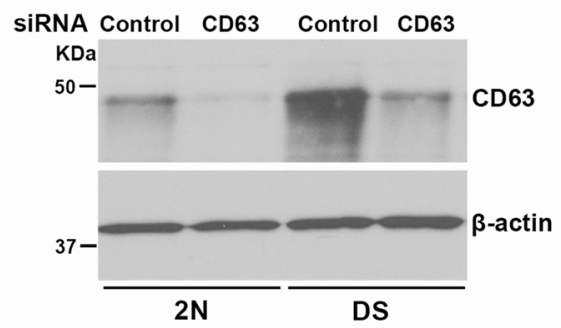

C

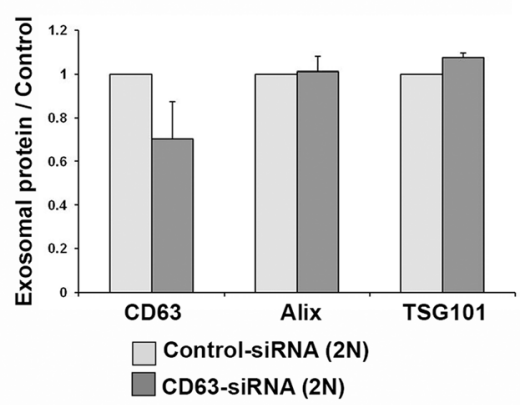

e

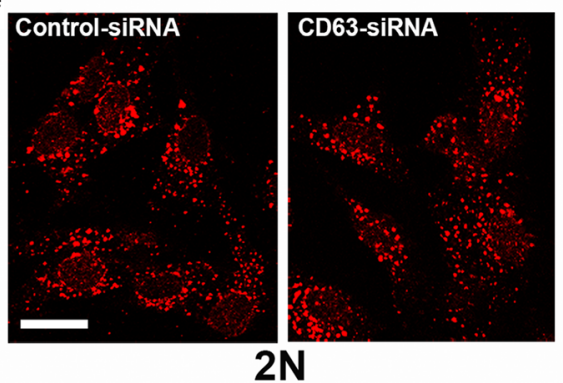

$\mathbf{f}$

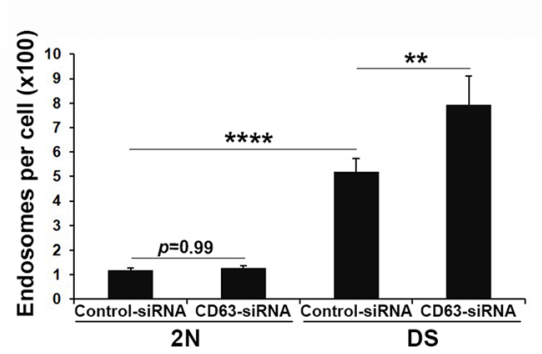

b

\section{Fibroblast EVs}

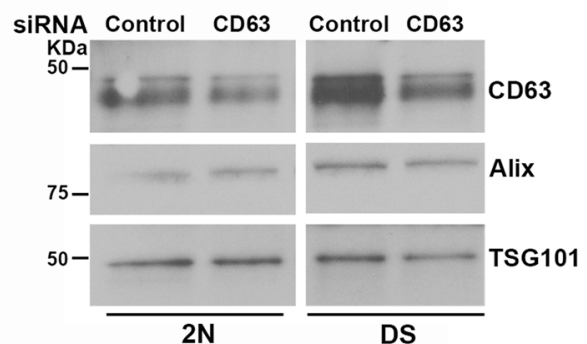

d
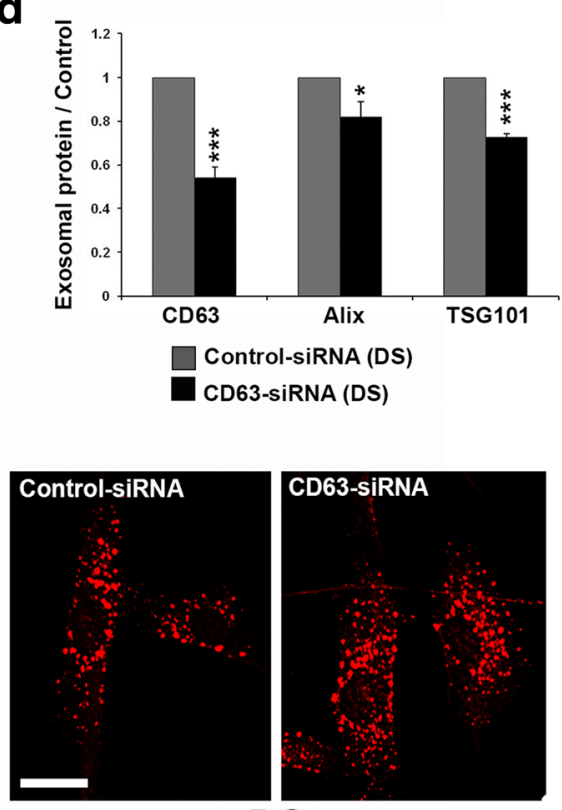

DS

g

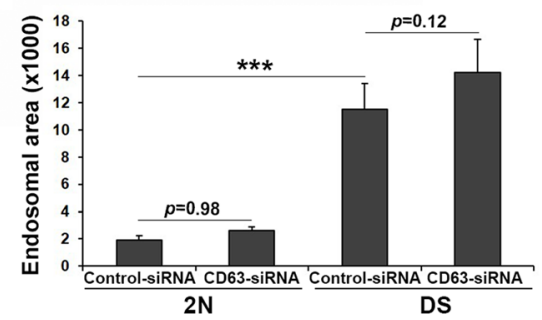

Fig. 5 Effect of CD63 knockdown on exosome secretion and endosomal pathology in DS cells. 2N and DS fibroblasts were transfected with either CD63 or negative control siRNAs. a CD63 knockdown was confirmed by Western-blot analysis of cell lysates. b Over 3 days, exosomes were collected from the cell culture media and quantified by Western-blot analysis for the exosomal markers CD63, TSG101, and Alix. c No significant changes were observed in exosome release by $2 \mathrm{~N}$ cells following CD63 silencing compared to controls. $\mathbf{d}$ DS fibroblasts in which CD63 was silenced showed decreased release of exosomes as seen by lower levels of exosomal TSG101 and Alix as compared to control DS cells. Student t-test, $n=4$ independent experiments ( ${ }^{*} p<0.05 ;{ }^{* * *} p<0.001$ ). e Early endosomes were immunolabeled with an anti-EEA1 antibody of transfected $2 \mathrm{~N}$ and DS cells (calibration bar $=20 \mu \mathrm{m})$. $\mathbf{f}$ No significant changes in the endosomal number were detected in CD63-reduced 2N fibroblasts compared to control $2 \mathrm{~N}$ cells, while a significant increase in number of endosomes was observed in DS cells following CD63 knockdown. $\mathbf{g}$ No significant differences were found in the area occupied by endosomes in 2N and DS cells after knocking down CD63, however DS fibroblasts showed a trend for an increase. Note that the number and area occupied by endosomes in DS fibroblasts is significantly higher than in $2 \mathrm{~N}$ under basal (control-siRNA) conditions (f, $\mathbf{g}$ ). Area is expressed in pixels per cell. One-way ANOVA followed by Tukey post-hoc multiple comparison test, $n=4$ independent experiments $\left({ }^{* *} p<0.01\right.$; ${ }^{* *} p<0.001$; $\left.{ }^{* * * *} p<0.0001\right)$ 


\section{Diploid control}

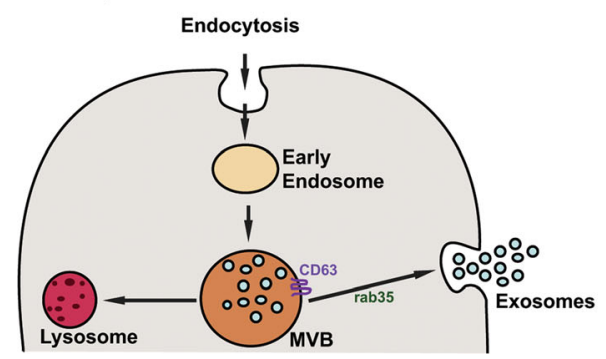

Down syndrome

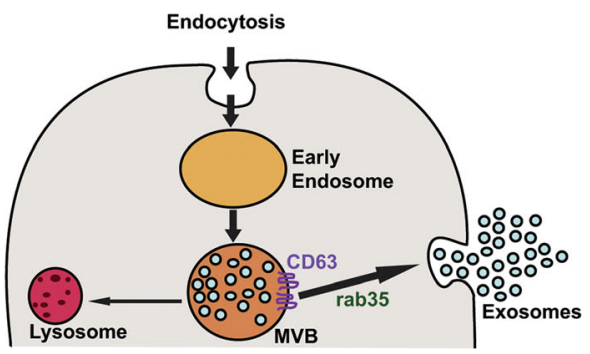

Fig. 6 Schematic representation of the endosomal and exosomal pathways in diploid and DS neurons. Endocytosed material in the cell is transported by early endosomes and late endosomes/multivesicular bodies (MVBs) for either degradation in lysosomes or exosome secretion. The invagination of the MVBs membrane results in the formation of intraluminal vesicles (ILVs), which are released as exosomes into the extracellular space upon fusion of MVBs with the plasma membrane. Our findings show that in DS neurons with endosomal enlargement there is an enhanced exosome release regulated by the tetraspanin CD63

exosomes [19]. Moreover, we report that CD63 transcription is enhanced in the brains of Ts2 mice. In contrast, higher levels of protein expression, but not mRNA was found for rab35, a regulator of exosome secretion [24]. We suggest that higher rab35 protein levels may be downstream of the induction of CD63, in response to ILVs accumulation by releasing excess MVBs load into the extracellular space. Upregulation of CD63 gene rules out the possibility that higher CD63 protein levels in DS is due to its accumulation as a consequence of endosomal pathology. We then investigated whether enhanced exosome secretion by CD63 has a role in alleviation of endosomal pathology. DS fibroblasts secreted more exosomes into the cultured media compared to $2 \mathrm{~N}$ cells and CD63 knockdown reduced exosome secretion by the DS cells. In support of an inter-relationship between exosomal release and endosomal pathology, CD63 knockdown also caused changes in endosomes of DS fibroblasts, characteristic of the endosomal abnormalities reported in DS patients [10], DS fibroblasts [8], and in DS mouse models $[9,26]$. These data argue that partially blocking exosome release in cells with endosomal pathology aggravates the intracellular accumulation of endosomal membranes. In contrast, in normal cells without endosomal pathology, silencing CD63 did not affect exosome release or endosome accumulation, implying that exosome release can be regulated in $2 \mathrm{~N}$ cells even under changes in expression of proteins involved in exosome generation, while DS cells lose this capability. Therefore, these data suggest that CD63 is involved in the formation of more ILVs in MVBs when the system is compromised, similar to the finding that CD63 overexpression is associated with higher exosome release in fibroblasts from patients with systemic sclerosis [38]. It cannot be ruled out that in the diseased brain, this protective mechanism of the exosome secretory pathway to relieve DS neurons of accumulated endosomal contents might be outweighed by the propagation of toxic material by exosomes throughout the brain. The ability of exosomes to promote the spread of the disease has emerged as a general mechanism of propagation of neurodegenerative disorders $[23,56]$ and it was recently reported that neuronal exosomes obtained from blood of DS patients have elevated levels of amyloid- $\beta$ peptides and phosphorylated-tau [21]. Further, reducing exosome secretion has been suggested as a potential therapeutic intervention for $\mathrm{AD}[6,16]$. However, blocking exosome production resulted in exacerbated behavioral and pathological defects in a transgenic mouse overexpressing a mutant form of the toxic protein TDP-43 [25], negating inhibition of exosome release in neurodegenerative disorders as a therapeutic approach.

\section{Conclusions}

In summary, the data presented here show a role for exosomes in the regulation of endosomal function in DS, implicate CD63 in driving exosome release in the DS brain, and suggest that this is a protective mechanism to alleviate the endosomal pathology. Since the naturally occurring enhancement of exosome release in the brain of DS patients is not sufficient to alleviate the endosomal pathology, which is already observed in fetuses and worsens with age, therapeutic approaches that enhance exosome secretion even further may be beneficial. Indeed, apart from pathological proteins, exosomes naturally transport cargoes with therapeutic properties [31, 33, 34, 45] and can be engineered to target neurons while carrying specific molecules for therapeutics [5]. Increasing our knowledge of brain exosome secretion and its potential therapeutic effects is necessary to provide new insights into the mechanisms of disease and may help to develop novel therapeutic strategies for neurodegenerative disorders with accumulation of toxic material in endosomes, like DS and AD. 


\section{Additional file}

Additional file 1: Table S1. Proteins identified by LC-MS analysis of brain EVs that are part of the top 100 proteins frequently identified in exosomes (http://exocarta.org/exosome_markers_new). (DOC 149 kb)

\section{Abbreviations}

2N: normal disomic; AChE: Acetylcholine esterase; AD: Alzheimer's disease; BA9: Brodmann area 9; DMEM: Dulbecco's modified Eagle's medium; DS: Down Syndrome; ESCRT: Endosomal sorting complexes required for transport; EVs: Extracellular vesicles; FBS: Fetal bovine serum; HA: Hibernate A; ILVs: Intraluminal vesicles; MVBs: Multivesicular bodies

\section{Acknowledgements}

Not applicable.

\section{Funding}

This work was supported by the Alzheimer's Association (NIRG-14-316,622), the National Institute of Neurological Disorders and Stroke (P30 NS050276), the National Center for Research Resources (S10RR027990), and the National Institute on Aging (AG017617, AG037693, AG043375, and AG014449).

\section{Availability of data and materials}

The datasets generated and/or analyzed during the current study are not publicly available yet because we are still collecting and analyzing data that will be available when the study is complete.

\section{Authors' contributions}

EL conceived the ideas. SAG and RPG designed, performed, and analyzed experiments. AS contributed to EVs isolation and Western-blot analysis. GK performed the immunocytochemistry experiments on fibroblasts. FH and TN performed the proteomic analysis. MJA and SDG performed the GPCR analysis. MP maintained the Ts2 mouse colony. RPG, SAG and EL wrote the manuscript. All authors read and approved the final manuscript.

\section{Ethics approval}

All animal procedures were performed following the National Institutes of Health guidelines with approval from the Institutional Animal Care and Use Committee at the Nathan S. Kline Institute for Psychiatric Research.

\section{Consent for publication}

Not applicable.

\section{Competing interests}

The authors declare that they have no competing interests.

\section{Publisher's Note}

Springer Nature remains neutral with regard to jurisdictional claims in published maps and institutional affiliations.

\begin{abstract}
Author details
${ }^{1}$ Center for Dementia Research, Nathan S. Kline Institute for Psychiatric Research, Orangeburg, NY 10962, USA. ${ }^{2}$ Cell Biology and Skirball Institute of Biomolecular Medicine, NYU Langone School of Medicine, New York, NY 10016, USA. ${ }^{3}$ Department of Psychiatry, NYU Langone School of Medicine, New York, NY 10016, USA. ${ }^{4}$ Department of Neuroscience \& Physiology, NYU Langone School of Medicine, New York, NY 10016, USA. ${ }^{5}$ Neuroscience Institute, NYU Langone School of Medicine, New York, NY 10016, USA. DDepartment of Biochemistry \& Molecular Pharmacology, NYU Langone School of Medicine, New York, NY 10016, USA.
\end{abstract}

Received: 17 August 2017 Accepted: 17 August 2017 Published online: 29 August 2017

\section{References}

1. Alldred MJ, Che S, Ginsberg SD (2008) Terminal Continuation (TC) RNA amplification enables expression profiling using minute RNA input obtained from mouse brain. Int J Mol Sci 9:2091-2104. doi: 10.3390/ijms9112091
2. Alldred MJ, Duff KE, Ginsberg SD (2012) Microarray analysis of CA pyramidal neurons in a mouse model of tauopathy reveals progressive synaptic dysfunction. Neurobiol Dis 45:751-762 doi:S0969-9961(11)00354-8

3. Alldred MJ, Lee SH, Petkova E, Ginsberg SD (2015) Expression profile analysis of hippocampal CA1 pyramidal neurons in aged Ts65Dn mice, a model of Down syndrome (DS) and Alzheimer's disease (AD). Brain Struct Funct 220: 2983-2996. doi: 10.1007/s00429-014-0839-0

4. Alldred MJ, Lee SH, Petkova E, Ginsberg SD (2015) Expression profile analysis of vulnerable CA1 pyramidal neurons in young-Middle-Aged Ts65Dn mice. J Comp Neurol 523:61-74. doi: 10.1002/cne.23663

5. Alvarez-Erviti L, Seow Y, Yin H, Betts C, Lakhal S, Wood MJ (2011) Delivery of siRNA to the mouse brain by systemic injection of targeted exosomes. Nat Biotechnol 29:341-345. doi: 10.1038/nbt.1807

6. Asai H, Ikezu S, Tsunoda S, Medalla M, Luebke J, Haydar T, Wolozin B, Butovsky O, Kugler S, Ikezu T (2015) Depletion of microglia and inhibition of exosome synthesis halt tau propagation. Nat Neurosci 18:1584-1593. doi: 10.1038/nn.4132

7. Cataldo AM, Barnett JL, Pieroni C, Nixon RA (1997) Increased neuronal endocytosis and protease delivery to early endosomes in sporadic Alzheimer's disease: neuropathologic evidence for a mechanism of increased beta-amyloidogenesis. J Neurosci 17:6142-6151

8. Cataldo AM, Mathews PM, Boiteau AB, Hassinger LC, Peterhoff CM, Jiang $Y$, Mullaney K, Neve RL, Gruenberg J, Nixon RA (2008) Down syndrome fibroblast model of Alzheimer-related endosome pathology: accelerated endocytosis promotes late endocytic defects. Am J Pathol 173:370-384 doi: S0002-9440(10)61614-8

9. Cataldo AM, Petanceska S, Peterhoff CM, Terio NB, Epstein CJ, Villar A, Carlson EJ, Staufenbiel M, Nixon RA (2003) App gene dosage modulates endosomal abnormalities of Alzheimer's disease in a segmental trisomy 16 mouse model of down syndrome. J Neurosci 23:6788-6792 doi:23/17/6788

10. Cataldo AM, Peterhoff CM, Troncoso JC, Gomez-Isla T, Hyman BT, Nixon RA (2000) Endocytic pathway abnormalities precede amyloid beta deposition in sporadic Alzheimer's disease and Down syndrome: differential effects of APOE genotype and presenilin mutations. Am J Pathol 157:277-286 doi: S0002-9440(10)64538-5

11. Charrin S, le Naour F, Silvie O, Milhiet PE, Boucheix C, Rubinstein E (2009) Lateral organization of membrane proteins: tetraspanins spin their web. Biochem J 420:133-154 doi:BJ20082422

12. Colombo M, Raposo G, Thery C (2014) Biogenesis, secretion, and intercellular interactions of exosomes and other extracellular vesicles. Annu Rev Cell Dev Biol 30:255-289. doi: 10.1146/annurev-cellbio-101512-122326

13. Cox J, Matic I, Hilger M, Nagaraj N, Selbach M, Olsen JV, Mann M (2009) A practical guide to the MaxQuant computational platform for SILAC-based quantitative proteomics. Nat Protoc 4:698-705. doi: 10.1038/nprot.2009.36

14. Cox J, Neuhauser N, Michalski A, Scheltema RA, Olsen JV, Mann M (2011) Andromeda: a peptide search engine integrated into the MaxQuant environment. J Proteome Res 10:1794-1805. doi: 10.1021/pr101065j

15. Davisson MT, Schmidt C, Akeson EC (1990) Segmental trisomy of murine chromosome 16: a new model system for studying Down syndrome. Prog Clin Biol Res 360:263-280

16. Dinkins MB, Dasgupta S, Wang G, Zhu G, Bieberich E (2014) Exosome reduction in vivo is associated with lower amyloid plaque load in the 5XFAD mouse model of Alzheimer's disease. Neurobiol Aging 35:1792-1800 doi:S0197-4580(14)00204-8

17. Eitan E, Suire C, Zhang S, Mattson MP (2016) Impact of lysosome status on extracellular vesicle content and release. Ageing Res Rev 32:65-74 doi: S1568-1637(16)30077-0

18. Ginsberg SD, Mufson EJ, Counts SE, Wuu J, Alldred MJ, Nixon RA, Che S (2010) Regional selectivity of rab5 and rab7 protein upregulation in mild cognitive impairment and Alzheimer's disease. J Alzheimers Dis 22:631-639 doi:30718UGL13V2H023

19. Guix FX, Sannerud R, Berditchevski F, Arranz AM, Horre K, Snellinx A, Thathiah A, Saido T, Saito T, Rajesh S, Overduin M, Kumar-Singh S, Radaelli E, Corthout N, Colombelli J, Tosi S, Munck S, Salas IH, Annaert W, De Strooper B (2017) Tetraspanin 6: a pivotal protein of the multiple vesicular body determining exosome release and lysosomal degradation of amyloid precursor protein fragments. Mol Neurodegener 12:25. doi: 10.1186/s13024-017-0165010.1186/s13024-017-0165-0

20. Hamlett ED, Boger HA, Ledreux A, Kelley CM, Mufson EJ, Falangola MF, Guilfoyle DN, Nixon RA, Patterson D, Duval N, Granholm AC (2016) Cognitive Impairment, Neuroimaging, and Alzheimer Neuropathology in Mouse Models of Down Syndrome. Curr Alzheimer Res 13:35-52 doi:CAR-EPUB-70523 
21. Hamlett ED, Goetzl EJ, Ledreux A, Vasilevko V, Boger HA, LaRosa A, Clark D, Carroll SL, Carmona-Iragui M, Fortea J, Mufson EJ, Sabbagh M, Mohammed AH, Hartley D, Doran E, Lott IT, Granholm AC (2017) Neuronal exosomes reveal Alzheimer's disease biomarkers in Down syndrome. Alzheimers Dement 13:541-549. doi: 10.1016/j.jalz.2016.08.012

22. Holtzman DM, Santucci D, Kilbridge J, Chua-Couzens J, Fontana DJ, Daniels SE, Johnson RM, Chen K, Sun Y, Carlson E, Alleva E, Epstein CJ, Mobley WC (1996) Developmental abnormalities and age-related neurodegeneration in a mouse model of Down syndrome. Proc Natl Acad Sci U S A 93:13333-13338

23. Howitt J, Hill AF (2016) Exosomes in the Pathology of Neurodegenerative Diseases. J Biol Chem 291:26589-26597. doi: 10.1074/jbc.R116.757955

24. Hsu C, Morohashi Y, Yoshimura S, Manrique-Hoyos N, Jung S, Lauterbach MA, Bakhti M, Gronborg M, Mobius W, Rhee J, Barr FA, Simons M (2010) Regulation of exosome secretion by Rab35 and its GTPase-activating proteins TBC1D10A-C. J Cell Biol 189:223-232. doi: 10.1083/jcb.200911018

25. Iguchi Y, Eid L, Parent M, Soucy G, Bareil C, Riku Y, Kawai K, Takagi S, Yoshida M, Katsuno M, Sobue G, Julien JP (2016) Exosome secretion is a key pathway for clearance of pathological TDP-43. Brain 139:3187-3201 doi:aww237

26. Jiang $Y$, Rigoglioso A, Peterhoff CM, Pawlik M, Sato Y, Bleiwas C, Stavrides P, Smiley JF, Ginsberg SD, Mathews PM, Levy E, Nixon RA (2016) Partial BACE1 reduction in a Down syndrome mouse model blocks Alzheimer-related endosomal anomalies and cholinergic neurodegeneration: role of APP-CTF. Neurobiol Aging 39:90-98 doi:S0197-4580(15)00580-1

27. Johnstone RM, Bianchini A, Teng K (1989) Reticulocyte maturation and exosome release: transferrin receptor containing exosomes shows multiple plasma membrane functions. Blood 74:1844-1851

28. Kalra H, Drummen GP, Mathivanan S (2016) Focus on Extracellular Vesicles: Introducing the Next Small Big Thing. Int J Mol Sci 17:170. doi: 10.3390/ ijms17020170

29. Kaur G, Sharma A, Xu W, Gerum S, Alldred MJ, Subbanna S, Basavarajappa BS, Pawlik M, Ohno M, Ginsberg SD, Wilson DA, Guilfoyle DN, Levy E (2014) Glutamatergic transmission aberration: a major cause of behavioral deficits in a murine model of Down's syndrome. J Neurosci 34:5099-5106 doi:34/15/5099

30. Kowal J, Tkach M, Thery C (2014) Biogenesis and secretion of exosomes. Curr Opin Cell Biol 29:116-125 doi:S0955-0674(14)00057-X

31. Kramer-Albers EM, Ping Kuo-Elsner W (2016) Extracellular Vesicles: Goodies for the Brain? Neuropsychopharmacology 41:371-372. doi: 10.1038/npp. 2015.242

32. Levine S, Saltzman A, Levy E, Ginsberg SD (2009) Systemic pathology in aged mouse models of Down's syndrome and Alzheimer's disease. Exp Mol Pathol 86:18-22 doi:S0014-4800(08)00113-5

33. Lopez-Leal R, Court FA (2016) Schwann Cell Exosomes Mediate Neuron-Glia Communication and Enhance Axonal Regeneration. Cell Mol Neurobiol 36: 429-436. doi: 10.1007/s10571-015-0314-310.1007/s10571-015-0314-3

34. Lopez-Verrilli MA, Picou F, Court FA (2013) Schwann cell-derived exosomes enhance axonal regeneration in the peripheral nervous system. Glia 61: 1795-1806. doi: 10.1002/glia.22558

35. Lott IT (2012) Neurological phenotypes for Down syndrome across the life span. Prog Brain Res 197:101-121 doi:B978-0-444-54299-1.00006-6

36. Lott IT, Dierssen M (2010) Cognitive deficits and associated neurological complications in individuals with Down's syndrome. Lancet Neurol 9:623633 doi:S1474-4422(10)70112-5

37. McCulloch CE, Searle SR, Neuhaus JM (2011) Generalized, Linear, and Mixed Models, Second edn. John Wiley \& Sons, New York

38. Nakamura K, Jinnin M, Harada M, Kudo H, Nakayama W, Inoue K, Ogata A, Kajihara I, Fukushima S, Ihn H (2016) Altered expression of CD63 and exosomes in scleroderma dermal fibroblasts. J Dermatol Sci 84:30-39 doi: S0923-1811(16)30130-X

39. Nixon RA (2004) Niemann-Pick Type C disease and Alzheimer's disease: the APP-endosome connection fattens up. Am J Pathol 164:757-761 doi:S00029440(10)63163-X

40. Perez-Gonzalez R, Gauthier SA, Kumar A, Levy E (2012) The exosome secretory pathway transports amyloid precursor protein carboxyl-terminal fragments from the cell into the brain extracellular space. J Biol Chem 287: 43108-43115 doi:M112.404467

41. Perez-Gonzalez R, Gauthier SA, Kumar A, Saito M, Levy E (2017) A Method for Isolation of Extracellular Vesicles and Characterization of Exosomes from Brain Extracellular Space. Methods Mol Biol 1545:139-151. doi: 10.1007/9781-4939-6728-5_10

42. Pols MS, Klumperman J (2009) Trafficking and function of the tetraspanin CD63. Exp Cell Res 315:1584-1592 doi:S0014-4827(08)00393-5
43. Rappsilber J, Mann M, Ishihama Y (2007) Protocol for micro-purification, enrichment, pre-fractionation and storage of peptides for proteomics using StageTips. Nat Protoc 2:1896-1906 doi:nprot.2007.261

44. Salehi A, Delcroix JD, Belichenko PV, Zhan K, Wu C, Valletta JS, TakimotoKimura R, Kleschevnikov AM, Sambamurti K, Chung PP, Xia W, Villar A, Campbell WA, Kulnane LS, Nixon RA, Lamb BT, Epstein CJ, Stokin GB, Goldstein LS, Mobley WC (2006) Increased App expression in a mouse model of Down's syndrome disrupts NGF transport and causes cholinergic neuron degeneration. Neuron 51:29-42 doi:S0896-6273(06)00414-4

45. Sarko DK, McKinney CE (2017) Exosomes: Origins and Therapeutic Potential for Neurodegenerative Disease. Front Neurosci 11:82. doi: 10.3389/fnins. 2017.00082

46. Savina A, Vidal M, Colombo Ml (2002) The exosome pathway in K562 cells is regulated by Rab11. J Cell Sci 115:2505-2515

47. Scheltema RA, Hauschild JP, Lange O, Hornburg D, Denisov E, Damoc E, Kuehn A, Makarov A, Mann M (2014) The Q Exactive HF, a Benchtop mass spectrometer with a pre-filter, high-performance quadrupole and an ultrahigh-field Orbitrap analyzer. Mol Cell Proteomics 13:3698-3708. doi: 10. 1074/mcp.M114.043489

48. Shevchenko A, Wilm M, Vorm O, Mann M (1996) Mass spectrometric sequencing of proteins silver-stained polyacrylamide gels. Anal Chem 68:850-858

49. Strauss K, Goebel C, Runz H, Mobius W, Weiss S, Feussner I, Simons M Schneider A (2010) Exosome secretion ameliorates lysosomal storage of cholesterol in Niemann-Pick type C disease. J Biol Chem 285:26279-26288. doi: 10.1074/jbc.M110.134775

50. Thery C, Amigorena S, Raposo G, Clayton A (2006) Isolation and characterization of exosomes from cell culture supernatants and biological fluids. Curr Protoc Cell Biol Chapter 3:Unit 3 22. doi: 10.1002/0471143030. cb0322s30

51. van der Pol E, Boing AN, Harrison P, Sturk A, Nieuwland R (2012) Classification, functions, and clinical relevance of extracellular vesicles. Pharmacol Rev 64:676-705. doi: 10.1124/pr.112.005983

52. Villar AJ, Belichenko PV, Gillespie AM, Kozy HM, Mobley WC, Epstein CJ (2005) Identification and characterization of a new Down syndrome model, $\operatorname{Ts}[\mathrm{Rb}(12$. 1716)]2Cje, resulting from a spontaneous Robertsonian fusion between T(171)65Dn and mouse chromosome 12. Mamm Genome 16:79-90

53. Wang $X$, Huang $T, B u$ G, Xu H (2014) Dysregulation of protein trafficking in neurodegeneration. Mol Neurodegener 9:31. doi: 10.1186/1750-1326-9-31

54. Wisniewski KE, Laure-Kamionowska M, Wisniewski HM (1984) Evidence of arrest of neurogenesis and synaptogenesis in brains of patients with Down's syndrome. N Engl J Med 311:1187-1188. doi: 10.1056/NEJM198411013111818

55. Wisniewski KE, Wisniewski HM, Wen GY (1985) Occurrence of neuropathological changes and dementia of Alzheimer's disease in Down's syndrome. Ann Neurol 17:278-282. doi: 10.1002/ana.410170310

56. Xiao T, Zhang W, Jiao B, Pan CZ, Liu X, Shen L (2017) The role of exosomes in the pathogenesis of Alzheimer' disease. Transl Neurodegener 6:3. doi: 10.1186/s40035-017-0072-x72

\section{Submit your next manuscript to BioMed Central and we will help you at every step:}

- We accept pre-submission inquiries

- Our selector tool helps you to find the most relevant journal

- We provide round the clock customer support

- Convenient online submission

- Thorough peer review

- Inclusion in PubMed and all major indexing services

- Maximum visibility for your research

Submit your manuscript at www.biomedcentral.com/submit
Biomed Central 